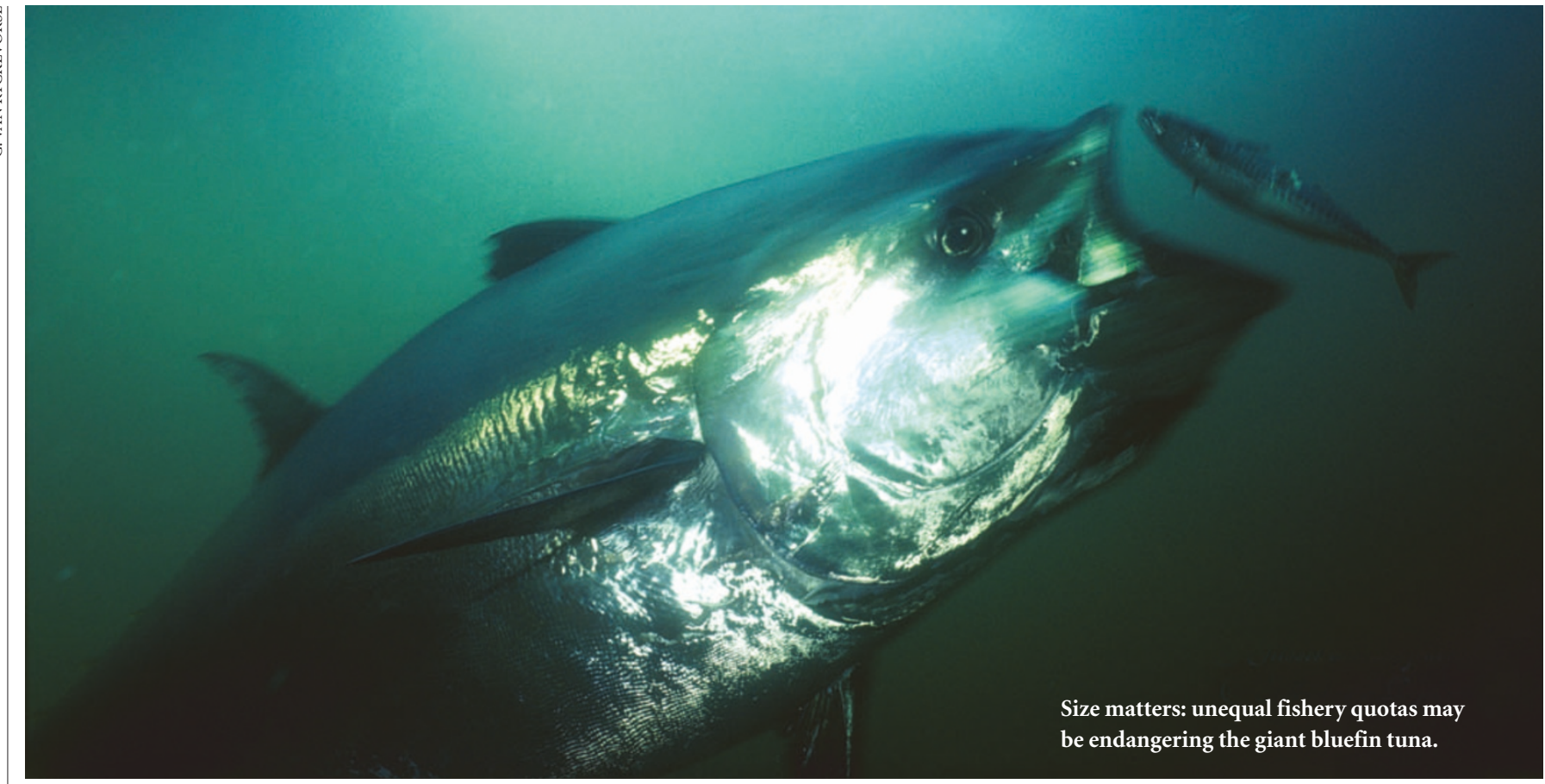

\title{
Satellite tags give fresh angle on tuna quota
}

\section{Rex Dalton}

The migration patterns of giant Atlantic bluefin tuna have been unravelled through satellite tagging - and the results suggest that policies for managing the overfished species require an urgent rethink.

Bluefin are huge marine predators that can weigh up to 650 kilograms and are prized for their flesh. They are the most valuable fish in the ocean - in Japan, single fish can command prices of up to US $\$ 100,000$. In recent decades, fishing boats have scrambled to catch as many as possible by trap, net, harpoon or longline, and as a result bluefin numbers have fallen by $80 \%$ or more since 1970 .

Atlantic bluefin (Thunnus thynnus) have two spawning grounds - the Gulf of Mexico and the Mediterranean. The gulf is the more heavily fished, so it is given greater protection by the International Commission for the Conservation of Atlantic Tunas (ICCAT), based in Madrid, Spain, which manages tuna stocks in international waters. ICCAT has set bluefin fishing quotas based on an imaginary line down the middle of the Atlantic: fishermen are allowed to catch 32,000 tonnes of bluefin a year to the east of the line, but only 3,000 tonnes to the west.

Scientists and conservationists have long been concerned about this policy, because they suspect that fish cross the dividing line when feeding in the open ocean. But until recently they had no way to prove it.

Now, a tagging study published in Nature (see page 1121) provides detailed information about bluefin movements. Getting these data wasn't easy. Over a nine-year period, Barbara Block of Stanford University, Cali- fornia, and her colleagues caught and tagged nearly 800 bluefin tuna. Global positioning data doesn't work when the fish are on deep dives, so the tags also collected detailed information such as light level and water temperature, which enabled researchers to piece together the course of each fish. Data were beamed back to a satellite, or retrieved after the fish was caught (the team offered a $\$ 1,000$ reward for each one returned).

Using the data from the tags, Block and her colleagues confirm that there are two separate populations of bluefin in the Atlantic, and each returns to the spawning ground from which it came. Crucially, the researchers also find that the two populations merge when foraging in the open ocean, feeding on both sides of ICCAT's line. This means that fish from more fragile western stocks are being caught as part of the larger quotas in the east.

The researchers further showed that longline fishermen hunting the smaller and more abundant yellowfin tuna (Thunnus albacares) in the Gulf of Mexico are probably having a devastating effect on spawning

\section{Bayou fleet brings bluefin blues}

Along the Louisiana coast, where bayous provide countless routes to the open water of the Gulf of Mexico, a small fishing fleet is doing great harm to a giant of the sea.

Maybe 50 vessels steam out though the mists from a handful of tiny ports to string their hooks across the waters of the continental shelf in the northern reaches of the gulf. They are seeking the abundant yellowfin tuna that school there nearly all year round. But from April to June the same patch of sea plays host to rare bluefin tuna, which migrate there to spawn. Most bluefin never reach breeding age, which takes around a decade, so catching bluefin at a spawning ground increases the loss of potential offspring. And this makes the endangered species more vulnerable.

Dulac is a typical Louisiana fishing town. Almost all the boats are owned by Vietnamese fishermen, many of them refugees, and they form a cloistered community that is wary of outside inquiry. They go to sea for two weeks at a time, continuously setting their long lines.

Quotas for bluefin are set very low. However, that doesn't really make any difference - even if extra bluefin are thrown back straight away they always die, probably due to the stress of being dragged to the surface in these temperate waters.

Interviews with the fishermen, as well as fish buyers and US officials, indicate that one or two bluefin are killed for every line set. There are even tales of a single line catching ten of the mammoth creatures.

Tung Nguyen (pictured) has just docked his boat, Peaceful Lady. He says he has no bluefin aboard, only the 43 yellowfin he caught during his two-week trip. But he admits he does sometimes catch bluefin in the spring, and they weigh anything from 250 to 500 kilograms. He says the fish are spawning - he notices the plump, ripe ovaries of the big females 


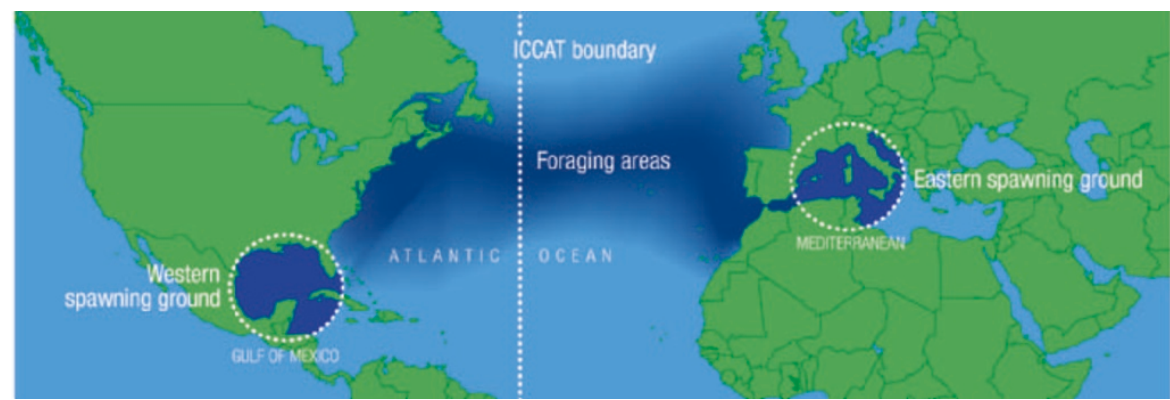

Fishing for complements: the International Commission for the Conservation of Atlantic Tunas divides bluefin stocks into east and west populations, but there is now evidence that they mix while foraging.

bluefin (see 'Bayou fleet brings bluefin blues'). Although there have been reports of bluefin being caught accidentally in the area, it has been hard for scientists to gauge the scale of the problem.

Block's team combined their location data on the bluefin in the gulf with information from the Maryland-based National Marine Fisheries Service (NMFS) on the movements of fishing boats. They show that the boats are dropping their lines in areas where bluefin gather.

Block hopes the tagging data will be used to set policies that will protect the fish better. "If we don't do something, bluefin stocks will collapse," she says. Block suggests dividing the Atlantic into more than two quota zones, and she wants longline fishing banned in certain parts of the Gulf of Mexico during the bluefin spawning season.

In the past, ICCAT has seemed reluctant to alter its policy, citing the need for more accurate accounts of fish movements. Scientists and conservationists alike hope that this study will fit the bill. "This is a very powerful paper," says John Magnuson, an ecologist at the University of Wisconsin, Madison, who has studied bluefin stocks. "New tagging tices for much of the bluefin's spawning methods mean that what was simply a matter of conjecture is becoming visible to us."

"It means we need to rethink bluefin management for the entire Atlantic," adds Paolo Guglielmi, a Rome-based biologist for the conservation group WWF.

The NMFS, which controls fishing pracgrounds in the northern Gulf of Mexico, was a part-funder of Block's study and will use the research to revise quotas for bluefin and other migratory Atlantic fish. "We are taking a fresh look," says NMFS economist Rebecca Lent. "We welcome this scientific information."

It is less clear whether ICCAT will change its policies when it sets new bluefin quotas next year. ICCAT officials met in Fukuoka, Japan, from 20 to 23 April to discuss management strategies for tuna and other migratory species. The meeting was partly sparked by Block's preliminary data, which were presented last May in Marseilles, France.

Officials have declined to discuss the outcome of the meeting. But ICCAT's chairman, Masanori Miyahara, cautions that the tagging data should be combined with studies of bluefin ovaries to pin down precisely when and where the fish are spawning.

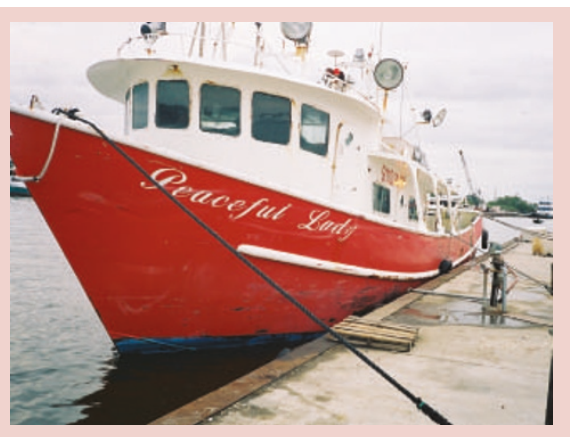

when he cleans them for market.

Barbara Block of Stanford University, California, and her colleagues have provided the best data so far on the potential impact of the fishery here. They will continue to monitor the fish they have tagged, and as the spawning season begins off Louisiana, researchers around the Atlantic will be watching with more interest than ever. Peaceful Lady, and vessels like her, may find that new political forces buffet future trips to sea. Rex Daliton, Dulac

\section{Physicists look to crystal device for future of fusion}

Mark Peplow, London

Seth Putterman is usually on the side of the sceptics when it comes to tabletop fusion. But now he has created a device that may convince researchers to change their minds about the 'f-word'.

Tabletop fusion has been a touchy subject since Stanley Pons and Martin Fleischmann said in 1989 that they had achieved 'cold fusion' at room temperature. Putterman helped to discredit this claim, as well as more recent reports of 'bubble fusion'.

Now Putterman, a physicist at the University of California, Los Angeles, has turned a tiny crystal into a particle accelerator. When its electric field is focused by a tungsten needle, it fires deuterium ions into a target so fast that the colliding nuclei fuse to create a stream of neutrons.

Putterman is not claiming to have created a source of virtually unlimited energy, because the reaction isn't selfsustaining. But until now, achieving any kind of fusion in the lab has required bulky accelerators with large electricity supplies. Replacing that with a small crystal is revolutionary. "The amazing thing is that the crystal can be used as an accelerator without plugging it in to a power station," says Putterman.

Putterman got the idea when he delivered a lecture on sonoluminescence and energy focusing at the Georgia Institute of Technology, Atlanta. Physicist Ahmet Erbil suggested that Putterman should instead consider ferroelectricity.

"Here's someone telling me in front of 100 people that I'm working on the wrong thing," recalls Putterman. But the comment got him started on his fusion reactor. The result is published in this week's Nature (see page 1115).

Will he be able to avoid the controversy that has dogged other fusion claims? "My first reaction when I saw the paper was 'oh no, not another tabletop fusion paper'," says Mike Saltmarsh, an acclaimed neutron hunter who was called in to resolve the dispute over bubble fusion. "But they've built a neat little accelerator. I'm pretty sure no one has been able to generate neutrons in this way before."

Putterman himself isn't worried. "If people think this is a crackpot paper that's just fine," he says. "We're right. Any scientist who says this is too wonderful to believe is welcome to reproduce the experiments." 